\title{
Analysis of Strategy to Improve the Quality of "the Last Kilometer" Distribution Service
}

\author{
Guangqian Xin \\ Business School, Shandong University of Technology \\ Zibo, China \\ Email: 1192677927 [AT] qq.com
}

\begin{abstract}
Due to the rise of modern online shopping, it has become an important force to promote the development of e-commerce. E-commerce is growing rapidly, the volume of express delivery business has increased, the quality of "last kilometer" delivery service is particularly important. In this paper, analytic hierarchy process $(\mathrm{AHP})$ is used to find out the main factors of affecting the quality of delivery service in the "last kilometer ", so as to put forward the strategy of improving the quality of distribution service.
\end{abstract}

Keywords--- Electronic Commerce, the Last Kilometer, Distribution

\section{BACKGROUND}

In recent years, China's e-commerce has developed rapidly, and its growth rate has reached 30\%. From the perspective of the scale of logistics industry, China's logistics industry has been maintaining a steady growth trend. From the point of view of logistics efficiency, China's logistics cost has decreased, but compared with western developed countries, it is still higher. Among them, the distribution cost accounts for about $30 \%$ of the logistics cost, so it is particularly important to strictly control the distribution cost. At the same time the last kilometer of distribution directly touches customers, affects logistics costs and user experience. When we concerne the cost, the problem of customer satisfaction should also be paid attention to.

\section{ANALYSIS OF INFLUENCING FACTORS OF DISTRIBUTION SERVICE QUALITY IN THE LAST KILOMETRE}

At present, customer satisfaction of the last kilometer distribution service is not high, low customer satisfaction means that customer requirements are not met, there are many factors that can affect customer satisfaction, the last mile delivery timeliness, delivery price and service attitude of distribution are more important, using the analytic hierarchy process (AHP), finds out the importance of these three factors to improve customer satisfaction. Element comparison structure chart of AHP , Figure 1:

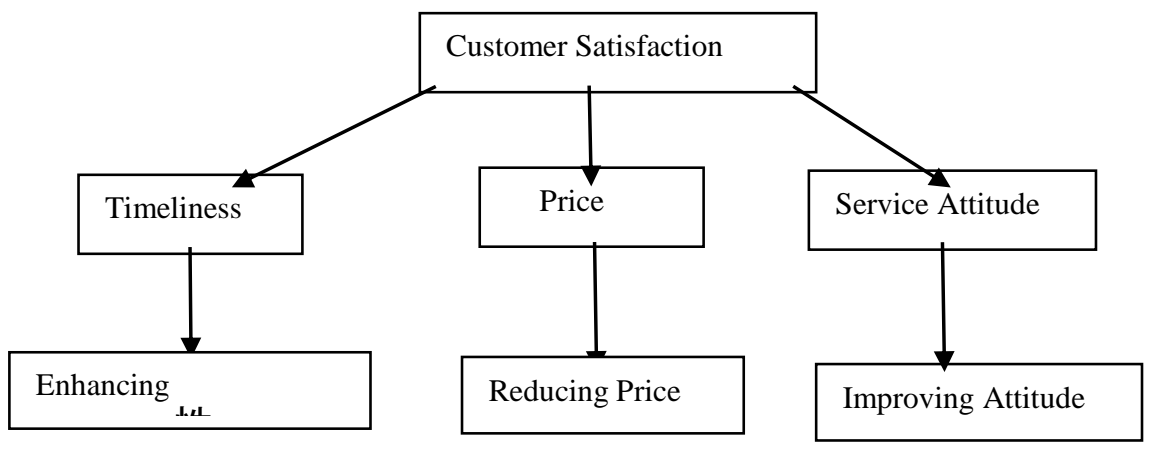

Figure 1 Element comparison structure chart of AHP

The structure chart indicates three factors that affect customer satisfaction, namely, the timeliness of delivery, the price of goods delivered and the service attitude during delivery. Let's call them A, B, and C, comparison of the importance of each indicator, Table 1:

Table 1 Comparison of the importance of each indicator

\begin{tabular}{|l|l|l|l|}
\hline importance & A & B & C \\
\hline A & 5 & 1 & 3 \\
\hline B & 1 & $1 / 5$ & $1 / 3$ \\
\hline C & 3 & $1 / 3$ & 1 \\
\hline
\end{tabular}


1 means relatively important, 3 means important, 5 means very important, and the important matrix is $\mathrm{H}$

$$
H=\left|\begin{array}{ccc}
5 & 1 & 3 \\
1 & 1 / 5 & 1 / 3 \\
3 & 3 / 3 & 1
\end{array}\right|
$$

According to the summation method, the importance of delivery timeliness is 0.161 , the importance of delivery price is 0.633 and the importance of delivery service is 0.261 . The results show that the timeliness of delivery is considered the most important, followed by the service attitude of the delivery personnel and finally the price of delivery. Therefore, when optimizing the delivery service of the last kilometer, we should focus on solving the timeliness of distribution and the service attitude of distribution, which can also improve customer satisfaction to a large extent, establish a good image for the company's distribution link, and enhance the timeliness.

\section{STRATEGIES TO IMPROVE THE QUALITY OF DISTRIBUTION SERVICE IN THE LAST KILOMETRE}

(1) Establishing comprehensive distribution service center and implementing common distribution strategy

Due to the dispersed distribution of customers in the last kilometer and obvious differences in personalized demands, the distribution service of the same distribution point can be integrated to reduce the input of vehicles and personnel. We can integrate the distribution resources of different express delivery companies, establish a third party service center, strengthen the diversified treatment of distribution, and actively improve the satisfaction of terminal distribution service, so as to reduce the cost of the last kilometer distribution.

(2)The combination of multiple distribution methods can reduce the cost of the last kilometer distribution.

We can choose different distribution mode according to different distribution environment, the selection of distribution mode should consider the distribution cost, population density of distribution area, customer requirements, the type of goods delivered and other factors. At present, the delivery methods include customer self - pick, intelligent self - pick cabinet, home delivery, the three distribution modes have their own advantages in terms of distribution efficiency, distribution time and distribution cost. In general, the average delivery time of each order used by the customer self - pick station is the shortest, the total distance traveled is the shortest, the cost is the lowest and the distribution efficiency is the highest. Secondly, it is the intelligent self - pick cabinet and home delivery. From the point of view of distribution cost, customer self-pick is far superior to the other two modes of distribution. Therefore, as far as possible, it is necessary to adopt customer self-pick, as much as possible to achieve the purpose of saving cost. In this mode, it is necessary to carry out strategic cooperation with convenience stores and supermarkets. On the premise of reducing our own distribution costs, it can also promote the retail of partners' products and achieve win-win cooperation.

(3) Providing value-added services to improve customer satisfaction

In order to meet the diverse and personalized needs of customers, each Courier company carries out self-service upgrade. While doing a good job in the basic delivery of express business, they can increase the service content. For example, accepting the simple agent, agent storage, door-to-door pick-up and other diversified businesses, providing personalized services. At the same time, we can do some surveys on customer satisfaction and business expansion to provide reasonable value-added services.

(4)Strengthening the training of terminal delivery personnel to improve the service level

Since the terminal distribution personnel are in direct contact with customers, the company should strengthen the cultivation of the inventory management quality and customer service level of the terminal distribution personnel. Regular training can be given to managers in professional distribution management and other aspects, as well as knowledge in service attitude when communicating with customers, so as to improve customer service satisfaction. At the same time, a relatively reasonable reward and punishment system can be developed, so that terminal distribution managers have greater motivation to better complete their own work and optimize customer service level.

The sustainable development of e-commerce cannot be separated from the support of the logistics industry, and the "last kilometer" distribution is an important link between e-commerce and end-consumer satisfaction, and the rationality of distribution directly affects the sustainable development of e-commerce. Therefore, the delivery service of the last kilometer needs to adopt a more efficient way to provide customers with professional and personalized services, so as to improve customer satisfaction. 


\section{REFERENCES}

[1] Ren Xiaocui. Research on the "Last Mile" Distribution Strategy of College Express Delivery Based on Shared Logistics [J].Fortune Today (Chinese Intellectual Property Rights), 2020, (01): 60.

[2] Wang Ru, Mou Weizhe, Liu Min, Song Yiping, Xuan Lingna.Research on Logistics Distribution Problem Based on Campus Last Kilometer [J]. Northern Economy and Trade , 2018 , (12 ) :75-77.

[3] Zhan Bin, Gu Ziqi, Li Yang. Research on Optimization of "Last Kilometre" Distribution Mode of E-commerce Logistics under the Background of "Internet +" [J].Logistics technology, 2016, (01):1-411.

[4] Lu Huanhuan, Yan Shaoqing. Analysis of the "Last Mile" Distribution Problem of E-Commerce Based on Codistribution [J].Logistics technology, 2013, (10):116-118.

[5] Zheng Di. Research on the Cost of "Last Kilometer" Distribution Mode of E-commerce Logistics [J]. Logistics Science and Technology, 2015, (09):139-1. 